\title{
Thyroid Gland Anaplastic Carcinoma, Osteoclastic Variant
}

National Cancer Institute

\section{Source}

National Cancer Institute. Thyroid Gland Anaplastic Carcinoma, Osteoclastic Variant. NCI

Thesaurus. Code C7906.

An extremely rare morphologic variant of anaplastic carcinoma of the thyroid gland,

characterized by the presence of large numbers of non-neoplastic, osteoclast-like giant cells. 